\title{
FORMAÇÃO CIDADÃ NA EDUCAÇÃO CIENTÍFICA E TECNOLÓGICA: OLHARES CRÍTICOS E DECOLONIAIS PARA AS ABORDAGENS CTS
}

\author{
Citizen training in scientific and technological education: critical and decolonial views \\ for STS approaches
}

\author{
Formación ciudadana en educación científica y tecnológica: vistas críticas y \\ decoloniales para enfoques CTS
}

\author{
Victor Augusto Bianchetti Rodrigues* \\ Irlan von Linsingen * \\ Suzani Cassiani $^{*}$
}

\begin{abstract}
Resumo
As abordagens a partir das relações entre Ciência-Tecnologia-Sociedade (CTS) têm se destacado, no âmbito da Educação Científica e Tecnológica (ECT). Neste trabalho, nos dedicamos a investigar sobre as contribuições das abordagens CTS para a formação cidadã crítica e decolonial dos estudantes. Para isso, realizamos uma revisão na literatura, de maneira a analisar artigos sobre abordagens CTS no âmbito da ECT, com base em pressupostos de Paulo Freire, Boaventura de Sousa Santos, Maria Paula Meneses e Anibal Quijano. Foi possível perceber que a maioria das propostas CTS desenvolvidas no contexto brasileiro abordam temáticas que chamamos de "universais", pois não correspondem à realidade dos estudantes. Ademais, não foi possível perceber, nas propostas educacionais CTS, a denúncia da presença das relações de colonialidade e seus efeitos socioculturais. Nesse sentido, propomos uma ressignificação das abordagens CTS no contexto brasileiro, de maneira que as mesmas possam contribuir para uma formação cidadã crítica e decolonial.
\end{abstract}

PALAVRAS-CHAVE: Educação Científica e Tecnológica. Formação Cidadã. Decolonialidade.

\begin{abstract}
In Scientific and Technological Education (STE), one of the teaching trends that have stood out are the approaches from the relations between Science-Technology-Society (STS). In this work, we focus on investigating the contributions of STS approaches to the critical and decolonial citizenship. In order to do this, we review the literature to analyze articles on STS approaches, based on the assumptions of Paulo Freire, Boaventura de Sousa Santos, Maria Paula Meneses and Anibal Quijano. It was possible to perceive that most of the supposedly critical STS proposals, developed in the Brazilian context, approach themes that we will call "universal" because they do not correspond to the reality of the students. In addition, it was not possible to perceive in the STS educational proposals the denunciation of the presence of coloniality relations and their socio-

\footnotetext{
* Doutorando no Programa de Pós-Graduação em Educação Científica e Tecnológica (Universidade Federal de Santa Catarina). Professor de Química (Instituto Federal do Paraná). E-mail: victorbianchetti@gmail.com.

* Doutor em Educação em Ciências. Pós-Doutor pela Universidade de Coimbra (UC-PT). Professor Titular do Departamento de Mecânica e do Programa de Pós-Graduação em Educação Científica e Tecnológica (Universidade Federal de Santa Catarina). E-mail: irlan.von@gmail.com.

* Doutora em Educação. Pós-Doutora em Ciências Sociais (UC-PT). Professora Titular do Departamento de Metodologia de Ensino e do Programa de Pós-Graduação em Educação Científica e Tecnológica (Universidade Federal de Santa Catarina). E-mail: suzani.cassiani@ufsc.br.
} 
cultural effects. In this sense, we propose a re-signification of STS approaches in the Brazilian context, so that they can contribute to a critical and decolonial citizen formation.

KEYWORDS: Scientific and Technological Education. Citizenship. Decoloniality.

\section{Resumen}

En el ámbito de la Educación Científica y Tecnológica (ECT), una de las tendencias de enseñanza que se han destacado son los enfoques a partir de las relaciones entre Ciencia-Tecnología-Sociedad (CTS). En este trabajo, nos dedicamos a investigar sobre las contribuciones de los enfoques CTS para la formación ciudadana crítica y decolonial de los estudiantes. Para ello, realizamos una revisión en la literatura, de manera a analizar artículos sobre enfoques CTS en el ámbito de la ECT, con base en presupuestos de Paulo Freire, Boaventura de Sousa Santos y Anibal Quijano. Es posible percibir que la mayoría de las propuestas CTS desarrolladas en el contexto brasileño abordan temáticas que llamaremos "universales", pues no corresponden a la realidad de los estudiantes. Además, no fue posible percibir en las propuestas educativas CTS la denuncia de la presencia de las relaciones de colonialidad y sus efectos socioculturales. En este sentido, proponemos una resignificación de los enfoques CTS en el contexto brasileño, de manera que las mismas puedan contribuir a una formación ciudadana crítica y decolonial.

PALABRAS CLAVE: Educación Científica y Tecnológica. Formación ciudadana. Decolonialidad.

\section{INTRODUÇÃO}

Os objetivos da Educação Científica e Tecnológica (ECT) se deslocam constantemente em função do contexto social, político e econômico de cada tempo histórico. Ao longo da segunda metade do século passado, sobre forte influência dos Estados Unidos, o regime militar brasileiro censurou, estrategicamente, as investidas progressistas na educação básica. Naquele momento, a ECT tinha dois focos principais: o fortalecimento da ciência como uma forma de representação de poder; e a formação de profissionais para ocupar cargos operacionais na indústria de base - energia, telecomunicações, siderurgia, entre outros. Portanto, as formações cientificista e tecnicista/ profissionalizante prevaleciam em detrimento de uma formação com caráter humanístico (ROSA, 1999; KRASILCHIK, 2000).

$\mathrm{Na}$ década de 1990, novas diretrizes escolares surgiram acompanhadas da redemocratização advinda do fim do regime de ditadura militar. Em 1996, foi aprovada a Lei de Diretrizes e Bases da Educação (LDB), n 9.394/96, que ainda vincula a educação básica à preparação para o mundo do trabalho. Entretanto, a LDB 9.394/96 apresentou-se inovadora ao propor, também, que a educação básica deve estar relacionada à prática social. Destarte, a educação escolar passou a ter maior comprometimento com a formação cidadã (BRASIL, 1996).

Diante desse contexto, surgiram novas formas de se promover a educação escolar. No que se refere à ECT, houve inovações tanto nas abordagens de ensino e aprendizagem, quanto no conteúdo escolar. Dentre as tendências educacionais inovadoras, o ensino de Ciências, considerando aspectos das relações Ciência-Tecnologia-Sociedade (CTS), tem se destacado por sua potencialidade em formar cidadãos. Entretanto, conforme relatam alguns trabalhos, há grande diversidade de interpretações e de abordagens CTS, a depender, por exemplo, das leituras de documentos curriculares oficiais, da formação do professor, do 
contexto em que o processo escolar se realiza, entre outros. (LINSINGEN E CASSIANI, 2010; STRIEDER E KAWAMURA (2017).

Em decorrência dessa diversidade de abordagens CTS e considerando que um dos principais objetivos da educação escolar é a formação para o exercício da cidadania ${ }^{1}$, surgem alguns pontos de partida deste trabalho: em que medida as diferentes abordagens CTS, no âmbito da ECT, têm contribuído para o desenvolvimento da formação cidadã dos estudantes brasileiros?

Ao considerar nossos pressupostos teóricos, desdobramos essa questão principal em outras duas perguntas: (i) em que medida as temáticas abordadas nas propostas de ensino CTS proporcionam aos estudantes a possibilidade de denunciar as contradições vividas por eles?; e (ii) em que medida as propostas de ensino CTS propiciam aos estudantes o aprendizado de conhecimentos que os instrumentalizam a anunciar soluções para as contradições identificadas por eles? Sem pretender esgotar as respostas a essas questões, as reflexões aqui apresentadas podem contribuir para o desenvolvimento de práticas escolares socialmente referenciadas, que contribuam para a superação das estruturas opressoras da sociedade.

Neste trabalho, nos dedicamos a analisar parte do que é apresentado na literatura sobre as abordagens CTS na ECT. Avaliamos a pertinência dos temas abordados em propostas CTS para o desenvolvimento da formação cidadã dos estudantes brasileiros. Nossa avaliação parte da análise de artigos científicos publicados em periódicos da área. Para isso, nos apoiamos nos pressupostos de Paulo Freire, Boaventura de Sousa Santos e nos estudos decoloniais de Anibal Quijano.

\section{A formação cidadã no âmbito da educação científica e tecnológica}

Cidadania é um conceito polissêmico que sofre constantes deslocamentos em diferentes contextos (DAGNINO, 2004; TONET, 2005). Nesse sentido, é fundamental explicitar o que entendemos por formação cidadã e, mais do que isso, quais as características de um contexto escolar que promova tal formação. Para isso, sustentamos esse conceito nos pressupostos apresentados por Paulo Freire, no livro Pedagogia do Oprimido, publicado em 1968. Além disso, buscamos inspiração nas ideias de Boaventura de Sousa Santos, Maria Paula Meneses e nos autores decoloniais da latino-américa, sobretudo Anibal Quijano. Ao levar esses pressupostos em consideração, pensar a formação dos estudantes direcionada para a cidadania é um desafio que inevitavelmente deve partir do estudo sobre o contexto no qual os estudantes estão inseridos. No caso dos estudantes brasileiros, principalmente daqueles que percorrem a trajetória escolar em instituições de ensino público, esse contexto revela várias contradições, próprias de um país em desenvolvimento. Nesse sentido, defendemos que a ECT deve contribuir para uma formação cidadã crítica e decolonial para que essas contradições sejam superadas.

\section{Formação cidadã crítica e decolonial: afinal, do que estamos falando?}

\footnotetext{
${ }^{1}$ Na seção seguinte, abordamos a concepção de cidadania, crítica e decolonial, adotada neste trabalho.
} 
Para aprofundar nosso entendimento sobre formação cidadã em perspectiva crítica e decolonial, lançamos mão de Anibal Quijano ${ }^{2}$, Boaventura de Sousa Santos, Maria Paula Meneses e Paulo Freire. Quijano (1992) considera a existência de estruturas de poder que operam de maneira opressora, nos territórios em que houve colonização. Para o autor, essas estruturas perduram mesmo após a independência política das colônias, que continuam subalternizadas em relação às antigas metrópoles eurocentradas. Em outras palavras, para Quijano (1992), ainda que o colonialismo tenha findado, persistem relações de Colonialidade sobre as antigas colônias.

Quijano considera que as relações de Colonialidade estão arraigadas na negação da humanidade dos sujeitos que estão fora, sobretudo, dos padrões europeus. Sendo assim, é produzida uma invisibilidade histórica, na qual os conhecimentos produzidos por sujeitos latino-americanos, por exemplo, parecem não ter validade se não se adequarem aos padrões da ciência moderna hegemônica.

Para além do silenciamento de alguns conhecimentos, houve também a apropriação indevida de outros, que hoje são reconhecidos como produtos da Ciência hegemônica, mas que partiram de contextos alternativos à comunidade científica. Por exemplo, os conhecimentos ancestrais sobre plantas, em grande parte, foram desenvolvidos em comunidades indígenas (CASTRO-GOMEZ, 2010; GALANTE, 2011; HECKLER, 2006). Entretanto, não há referências a esses sujeitos nos artigos científicos da área, o que evidencia uma exploração epistêmica sofrida por esses sujeitos.

De acordo com Quijano, essa exploração se sustenta no

(...) fato de que os europeus ocidentais imaginaram ser a culminação de uma trajetória civilizatória desde um estado de natureza, [o que] levou-os também a pensar-se como os modernos da humanidade e de sua história, isto é, como o novo e ao mesmo tempo o mais avançado da espécie (QUIJANO, 1992, p. 122).

Nessa perspectiva, o eurocentrismo, abordado por Quijano, no trecho anterior, alimenta até hoje, a crença de que os sujeitos e os conhecimentos eurocentrados são mais valorizados, se tornando universais, enquanto outros, externos aos padrões europeus, são subalternizados e invisibilizados. A afirmação dos conhecimentos e sujeitos eurocentrados em detrimento daqueles desenvolvidos em territórios historicamente menosprezados, em que os sujeitos são considerados muitas vezes atrasados e sem direitos, promove uma linha abissal entre esses dois contextos (SOUSA SANTOS E MENESES, 2014).

A questão indígena no Brasil e na América Latina é um exemplo concreto desse silenciamento de sujeitos e conhecimentos socioculturalmente referenciados. Além da violência explícita e genocida que os indígenas sofreram no processo de colonização e continuam sofrendo, existe também uma violência epistêmica e moral. O que aprendemos e ensinamos sobre as culturas indígenas nas escolas, além da visão do homem branco sobre esses povos de múltiplas culturas? $\mathrm{O}$ que os homens e as mulheres indígenas têm a nos contar não é valorizado, justamente pela crença de que há superioridade daqueles que estão assentados nos padrões europeus, sendo este um dos danosos efeitos de colonialidade.

Quijano (1992) defende que o elemento determinante para o controle de um povo sobre os outros é a ideia de raça. Nesse sentido, há uma hierarquia racializada, em que os homens brancos, europeus, controlam e invisibilizam os negros e indígenas, ou qualquer

\footnotetext{
${ }^{2}$ Quijano, sociólogo peruano que fazia parte do grupo de pesquisa latino-americano modernidadecolonialidade, desenvolveu o conceito de colonialidade do poder.
} 
raça ${ }^{3}$ que não seja branca. O branco é naturalizado como o "normal" e o restante os "diferentes", trazendo efeitos de sentidos de branquitude, ao mesmo tempo, subalternizando os povos das colônias e explorando suas riquezas. Para essa relação de domínio, Anibal Quijano desenvolveu o conceito de "Colonialidade do Poder". Além da dominação a partir da raça, Quijano defende que a Colonialidade do Poder também atua sobre os sujeitos na medida em que eles se associam ou dissociam do gênero feminino e da condição de exploração laboral típica do capitalismo.

Portanto, ao considerar os pressupostos decoloniais de Quijano, defendemos que a formação cidadã deve ser oposta a esses efeitos da colonialidade, ou seja, decolonial. Esta formação está atrelada a práticas pedagógicas que proporcionam aos estudantes a construção de conhecimentos e práticas libertadoras, com potencial para superar as contradições presentes no contexto em que os mesmos estão inseridos. No caso dos estudantes brasileiros, há diversas relações de colonialidade que atuam sobre eles, os quais explicitaremos em seguida. Assumindo essa premissa, as contradições vivenciadas pelos estudantes estão diretamente associadas à raça, ao gênero e às condições de exploração no trabalho (típicas do sistema capitalista).

Diante do que foi exposto, consideramos que, para formar cidadãos, é necessário romper com os efeitos de colonialidade que atuam sobre nós. Em outras palavras, almejamos a decolonialidade como via de formação cidadã. Ao situar esta meta no nosso campo de atuação, é inevitável nos questionarmos sobre o papel da Ciência moderna hegemônica nesse movimento decolonial.

\section{O papel da Ciência moderna hegemônica para a formação cidadã}

Partindo desse questionamento, defendemos que conhecer os conceitos e a prática da Ciência e da Tecnologia é conhecer mais sobre mundo. Nesse sentido, o ensino de conceitos científicos pode ser adequado para que os estudantes compreendam de maneira mais apurada o contexto em que estamos inseridos. Entretanto, esse conhecimento não nos parece dar conta de propor soluções eficazes para as principais mazelas causadas pelas relações de colonialidade.

A Ciência moderna hegemônica tem sido o principal conhecimento que circula na maioria das sociedades. Porém, ao percebermos as profundas contradições que movem o planeta, ou seja, a crise ambiental, a desigualdade, o racismo, entre outras injustiças sociais, torna-se evidente que a produção e a prática científica não têm dado conta de solucionar essas questões. Para superar essas contradições, é preciso alterar a lógica de opressão em que estamos vivendo. Se há necessidade de ações inovadoras, valer-se exclusivamente do conhecimento científico - que têm sido a principal forma de conhecimento do mundo contemporâneo - não seria uma resolução de um conflito (ainda dentro da lógica opressora) em vez da superação de uma contradição?

Como exemplo, trazemos a questão do racismo. Cientificamente, já foi evidenciado e amplamente divulgado que não há diferenças raciais entre branc@s e negr@s. Entretanto, negr@s continuam subalternizados em relação aos branc@s, em inúmeros contextos. Ou

\footnotetext{
${ }^{3}$ É importante ressaltar que rechaçamos o conceito biológico de raça. Neste trabalho, assim como Quijano (2000), adotamos a ideia de raça em dimensão sociológica, como um instrumento de dominação social inventado para justificar o colonialismo e que ainda perdura nas relações de colonialidade.
} 
seja, o conhecimento científico moderno hegemônico tem um limite interno na resolução dessa contradição, pois a própria prática da Ciência é racista e machista, uma vez que é majoritariamente atribuída a homens brancos. Mesmo com importantes contribuições de representantes de diferentes etnias, o conhecimento científico não produz as condições que ensejam a superação do racismo enraizado na nossa sociedade, muito pelo contrário: ele produz e reproduz práticas racistas.

No caso da superação das contradições vinculadas ao racismo, os estudos étnicoraciais que resgatam e valorizam as contribuições d@s negr@s ao longo da história devem ser evidenciados. Esses conhecimentos, muitas vezes silenciados, certamente são mais eficazes na luta antirracista do que a Ciência moderna e podem contribuir para o desenvolvimento de uma Ciência contra-hegemônica. Pode-se questionar se é papel da ECT abordar o racismo que está na raiz da nossa sociedade. Porventura, alguns de nós, professores de ciências, consideram que isso é papel das ditas "humanidades". Entretanto, fazemos o seguinte questionamento: considerando que mais de $70 \%$ d@s jovens assasinad@s no Brasil são negr@s (WAISELFISZ, 2013), como promover uma educação para cidadania sem enfrentar o racismo? Quais sentidos de cidadania são possíveis ao fecharmos os olhos para o genocídio d@s jovens negr@s no Brasil?

Portanto, outros conhecimentos importantes, muitas vezes silenciados, podem/devem ser incorporados ao ensino de ciências. Esses conhecimentos, associados à Ciência moderna (em perspectiva contra-hegemônica) podem instrumentalizar os estudantes para o exercício da cidadania. Boaventura de Sousa Santos e Maria Paula Meneses (2014) nomeiam esses conhecimentos de Epistemologias do Sul e os define como um conjunto de práticas cognitivas desenvolvidas a partir das experiências dos grupos sociais que têm sofrido de maneira sistemática as injustiças do capitalismo, do colonialismo e do patriarcado - pressuposto que vai ao encontro das ideias de Quijano.

As localidades em que se encontram esses grupos sistematicamente silenciados são denominadas Sul Global e, segundo Boaventura de Sousa Santos (2006), nesses lugares atuam a lógica de Apropriação (dos recursos naturais, dos conhecimentos tradicionais) e de Violência (física, material, cultural e humana). Já as localidades onde estão presentes as elites dominantes são denominadas Norte Global, onde impera o paradigma da Regulação (controle social, ordem) e Emancipação (inclusão, distribuição de riquezas, conquista de direitos). É importante ressaltar que Sul e Norte globais não correspondem aos hemisférios geográficos e sim aos países conhecidos como "desenvolvidos" (Norte Global) e "em desenvolvimento" (Sul Global). Eles são separados por uma Linha Abissal, imaginária, que impossibilita a copresença dos dois hemisférios, silenciando sempre o Sul Global.

Historicamente, a Ciência moderna e hegemônica foi produzida pelas elites dominantes do Norte Global e parece estar a serviço delas, tornando invisíveis ou se apropriando indevidamente de outras formas de conhecimento do Sul Global que pudessem colocar em xeque os modos de dominação da modernidade (capitalismo, colonialismo e patriarcado). Por isso, Boaventura e Meneses (2014) defendem que essas contradições só podem ser superadas se outras formas de conhecimento forem utilizadas: as Epistemologias do Sul, nas quais abrem brechas para repensar outros saberes e dialogar com a ciência e a tecnologia contemporâneas.

Em consonância com a denúncia de Boaventura, Walsh (2009), uma das principais autoras do campo dos estudos decoloniais, afirma que a Ciência hegemônica desempenha um papel fundamental na manutenção das estruturas opressoras da sociedade, devido às 
condições de produção e por impossibilitar que os educandos proponham explicações autênticas e críticas para a realidade que os cercam. Nesse sentido, se faz necessário o desenvolvimento de novos marcos epistemológicos que rompam com a suposta neutralidade da ciência, de maneira a valorizar saberes socialmente referenciados, historicamente silenciados pela Ciência moderna hegemônica (WALSH, 2009).

Os estudos decoloniais, bem como as Epistemologias do Sul, apontam para práticas cognitivas que dão visibilidade a diversas visões de mundo. As articulações entre essa diversidade de conhecimentos podem propiciar a emancipação do saber, de maneira a valorizar o conhecimento produzido no contexto do Sul Global. A essa articulação entre saberes, Boaventura denomina de Ecologia de Saberes.

Entretanto, para realizar uma Ecologia de Saberes, é preciso identificar quais conhecimentos foram historicamente silenciados pelo Norte Global. Para isso, Boaventura propõe uma Sociologia das Ausências, que consiste justamente em identificar esses conhecimentos. Uma vez identificados, é necessário que se façam visíveis. A esse processo - de dar visibilidade aos conhecimentos até então silenciados - Boaventura dá o nome de Sociologia das Emergências.

Essas duas etapas iniciais para as Epistemologias do Sul podem ser exemplificadas pelo projeto Cinema no Interior. Segundo os idealizadores do projeto,

(...) o Cinema no Interior tem por objetivo contribuir com o desenvolvimento sociocultural de comunidades interioranas, utilizando como principal instrumento as ferramentas audiovisuais e a indústria cinematográfica. O projeto realiza pesquisas, oficinas de formação, filmes, livros fotográficos e mostras de cinema mantendo a própria comunidade local como principais pesquisadores, produtores, protagonistas e plateia inicial neste audacioso trabalho de intercâmbio e de valorização da cultura e classe artística interiorana ${ }^{4}$.

Em outras palavras, o projeto identifica culturas interioranas (Sociologia das Ausências) e dá visibilidade à produção dessas comunidades por meio das produções audiovisuais (Sociologia das Emergências).

A partir do momento em que conhecemos outras formas de conhecimento, dando voz aos sujeitos, para além da ciência moderna, podemos identificar quais deles podem ser articulados para superar algumas contradições da contemporaneidade, como o racismo. Boaventura de Sousa Santos (2006) defende que o conhecimento não é abstrato e sim uma prática de conhecimento. Nesse sentido, cada conhecimento terá um valor relativo, a depender do tipo de problema que se propõe resolver.

Assumindo esse pensamento, fazemos a defesa de que a ECT seja libertadora. De fato, a Ciência moderna pode contribuir para a libertação dos sujeitos, quando abordada em perspectiva contra-hegemônica. Para isso, é necessário: que se reconheça os seus limites internos na resolução dos problemas contemporâneos; e que outras formas de conhecimento sejam valorizadas e articuladas na resolução desses problemas, construindo uma Ecologia de Saberes (SOUSA SANTOS, 2006). Além disso, é necessário que sejam explicitadas as benesses e as mazelas que a produção e a articulação do conhecimento científico causam, de maneira a romper com a falácia da neutralidade científica. 4 Texto disponível no endereço eletrônico do projeto Cinema no Interior:
http://www.cinemanointerior.com.br/, acesso em 15 de fevereiro de 2019 . 
Ainda que tenhamos os pressupostos anteriores em mente, o grande desafio para nós, professores e pesquisadores da área de Educação Científica e Tecnológica é como implementar práticas decoloniais na ECT, contribuindo para a formação cidadã dos nossos estudantes. Diante disso, cabe nos apropriarmos das ideias de um dos principais educadores do mundo, o brasileiro Paulo Freire, que, não por acaso, tem sido atacado e censurado por conservadores e pela elite brasileira (MORTATTI, 2019).

Freire, em seu célebre livro Pedagogia do Oprimido, lançado em 1968, já dizia que os opressores pretendem transformar a mentalidade dos oprimidos para que eles se adaptem à situação e não a modifiquem. Por isso, qualquer ação que pretende potencializar o pensar autêntico dos cidadãos é vetada por mecanismos reacionários e conservadores, a fim de manter a estrutura social.

\section{Possíveis contribuições de Paulo Freire para uma Educação Científica e Tecnológica decolonial}

As articulações entre os estudos decoloniais, sobretudo de Anibal Quijano, as ideias de Boaventura Sousa Santos, Maria Paula Meneses e do educador brasileiro Paulo Freire podem contribuir para o desenvolvimento de um ensino socialmente referenciado e libertador. Segundo Freire (1987), a formação cidadã dos estudantes pode ser estabelecida na educação a partir da discussão sobre temas significativos para os mesmos. Diante disso, cabe ao educador, em parceria com os educandos, investigar o universo temático dos mesmos. O universo temático é constituído pelo conjunto de temas com potencial para ensejar o engajamento e protagonismo dos estudantes na busca por conhecimentos.

O campo da Teoria Crítica, ao qual Paulo Freire se aproxima, pode contribuir de maneira significativa para o processo de identificação de temáticas coerentes com o contexto brasileiro. Em oposição à Teoria Tradicional que entende a ciência como representação neutra da realidade, a Teoria Crítica (que tem Horkheimer e Adorno como expoentes) percebe a ciência moderna como produção cultural e ideológica que, portanto, não produz verdades absolutas (CARNAÚBA, 2010).

Nesse sentido, enquanto a Teoria Tradicional aponta para a adaptação à realidade e conformismo, a Teoria Crítica visa compreender a realidade de maneira a perceber as contradições nela presentes (denúncia) para que sejam propostas soluções com caráter libertador (anúncio), para a superação das contradições que foram identificadas. Portanto, ao almejar uma ECT libertadora, é importante proporcionar a compreensão da própria realidade (denúncia) e a transformação da mesma (anúncio), ou seja, uma formação cidadã crítica.

Paulo Freire se alinha ao campo da Teoria Crítica e concebe que o conhecimento da educação libertadora pode ser visto com um instrumento de transformação da realidade, ou seja, de proposição ativa de soluções para problemas da comunidade local. Esse movimento pode dar fim ao que Freire denomina "cultura do silêncio", uma vez que os educandos com formação crítica tendem a ser mais participativos nas tomadas de decisões e na identificação/construção e resolução de problemas, locais e globais da sociedade contemporânea.

A articulação dos pressupostos de Freire aos de Quijano, Meneses e Sousa Santos aqui proposta, pode favorecer uma formação cidadã escolar crítica, fornecendo instrumentos para a realização de denúncias e anúncios. Ademais, no contexto brasileiro, 
defendemos que a formação cidadã seja também decolonial, em oposição a todas as formas de desumanização, sobretudo o racismo, o machismo e a exploração da força de trabalho.

Nesse sentido, defendemos uma formação cidadã crítica e decolonial no âmbito da ECT, favorecendo aos estudantes: (i) a realização de denúncias das contradições típicas do Sul Global, marcadas por relações de colonialidade (racismo, patriarcado e capitalismo); e (ii) a proposição de anúncios, culminando em práxis inovadoras e alternativas para a superação dessas contradições. Diante disso, buscamos compreender em que medidas as abordagens CTS na ECT têm contribuído para o desenvolvimento da formação cidadã crítica e decolonial dos estudantes brasileiros.

\section{O movimento CTS e seus desdobramentos para a formação cidadã crítica e decolonial na educação científica e tecnológica}

A partir da segunda metade do século XX, a visão "salvacionista" da Ciência foi questionada, uma vez que parte de algumas sociedades, na Europa, nos Estados Unidos e na América Latina ${ }^{5}$, questionavam o modelo dominante de progresso científico e tecnológico. Esse desconforto potencializou reflexões e debates, que culminaram na origem e no desenvolvimento do movimento CTS - Ciência, Tecnologia e Sociedade (AULER; BAZZO, 2001; SANTOS, 2008; YAGER, 2000).

As principais pautas desse movimento giravam em torno a dois pressupostos: (i) o desenvolvimento científico e tecnológico é um processo social, uma vez que depende da produção humana e, portanto, não é um processo neutro, livre de ideologias; e (ii) as mudanças científicas e tecnológicas causam impactos positivos e negativos na sociedade e, portanto, as decisões sobre os rumos da ciência e da tecnologia devem ser de cunho democrático, em detrimento da tecnocracia normalmente empregada (ARGO, 2001).

No Brasil, as ideias do movimento CTS se tornaram mais evidentes a partir da década de 1990, no contexto do término da ditadura militar, principalmente no campo de pesquisa em ECT (CHRISPINO et al., 2013). Nesse sentido, sobre influência dessa e de outras correntes educacionais e em consonância com a LDB 9.394 de 1996, a ECT passou a ter como um de seus objetivos a formação de cidadãos capazes de articular os domínios da ciência, da tecnologia, da sociedade, para a tomada de decisões requeridas no exercício da cidadania.

Destarte, mesmo considerando que os pressupostos freireanos foram desenvolvidos no contexto da alfabetização e que há diferenças no processo de definição dos temas, alguns autores brasileiros (por exemplo: NASCIMENTO; LINSINGEN, 2006; ROSO; AULER, 2016; SANTOS, 2008; AULER; DELIZOICOV, 2006; STRIEDER, 2008) têm articulado os pressupostos da pedagogia libertadora de Paulo Freire aos do movimento CTS, tanto no que se refere ao processo de ensino e aprendizagem, quanto aos objetivos de formação.

A articulação entre os pressupostos de Freire e do movimento CTS favorece a promoção de um ensino a partir de problemas do contexto do estudante e o desenvolvimento de currículos de ensino sintonizados com as realidades e os interesses locais, que certamente contribui para a percepção da importância daquilo que é ensinado.

\footnotetext{
${ }^{5} \mathrm{Na}$ América Latina foi desenvolvido o Pensamento Latino Americano de Ciência, Tecnologia e Sociedade (PLACTS), que encontra em Oscar Varsavsky, Amílcar Herrera, Jorge Sábato, Máximo Halty e Marcel Roche, dentre outros, seus expoentes (LINSINGEN, 2007, p.7).
} 
Em se tratando do Brasil, no contexto do Sul Global, os temas, assim como os seus tratamentos educacionais, diferem em muito dos de países desenvolvidos. Questões ambientais no contexto do Sul Global, por exemplo, apresentam especificidades que as relacionam muito mais à lógica da Apropriação/Violência, do que a da Regulação/Emancipação. Ademais, temas como o do desenvolvimento da energia nuclear ou da engenharia genética competem com temas relevantes que afetam mais diretamente o cotidiano das pessoas em suas comunidades, necessitando o estabelecimento de uma escala de prioridades e tratamentos diferenciados.

Linsingen e Cassiani (2010) alertam para a importância de se considerar as contribuições dos estudos sociais da ciência e da tecnologia latino-americanos nas abordagens educacionais socialmente referenciadas e comprometidas, buscando propiciar aos estudantes uma formação cidadã crítica e decolonial. Conhecer seu entorno, sua condição latinoamericana, para identificar e compreender os problemas que se relacionam direta ou indiretamente com as questões locais, este seria o sentido educacional de buscar uma maior articulação com as correntes do Pensamento Latino Americano de CTS (PLACTS). Dessa maneira, ampliam-se substancialmente as propostas educacionais baseadas na definição prévia de temas e no tratamento universalizado de problemas, que algumas correntes da Educação CTS têm praticado.

Nesse sentido, o PLACTS pode ser valorizado e resgatado pelos professores e pesquisadores brasileiros, de maneira a potencializar a aprendizagem de concepções do movimento CTS coerentes com o nosso contexto. Sendo assim, ao considerar o nosso contexto, a necessidade de dar visibilidade ao PLACTS se torna ainda mais evidente

Ao resgatarmos o processo de elaboração dos PCNs, é possível compreender que os mesmos sofreram forte influência de grupos do movimento CTS europeu. Muitas vezes, os temas abordados em trabalhos de pesquisa que envolvem CTS no Brasil, acabam dando mais visibilidade para aqueles que não são tão emergenciais em nosso contexto, um dos efeitos de colonialidade do saber (PORTO-GONÇALVES, 2003). Para citar um exemplo, trazemos dois temas: o aquecimento global e a fome. Certamente os europeus tratarão com mais recorrência o primeiro tema, pois a fome não representa um grande problema naquele contexto. Já no Brasil, segundo o IBGE, em 2016: a renda domiciliar per capita era de R\$ 387 por mês, colocando $25,4 \%$ da população brasileira na situação de pobreza, ressaltando que desse total $72,9 \%$ eram pretos ou pardos.

Com base nessas premissas, discutimos aspectos das diferentes abordagens CTS no âmbito da ECT e suas pertinências, para uma formação cidadã crítica e decolonial. Na seção seguinte, apresentamos os caminhos metodológicos que percorremos para propor algumas reflexões sobre nossas questões de pesquisa.

\section{Caminhos metodológicos}

Para aprofundar o conhecimento sobre as temáticas que têm sido abordadas nas propostas CTS, realizamos uma revisão da literatura, de maneira a identificar trabalhos acadêmicos que se referem à ECT e CTS. Nossa investigação não pretende abarcar todas as propostas CTS realizadas no âmbito da ECT, tampouco buscamos esgotar as respostas para nossas questões de pesquisa.

A pesquisa se concretizou a partir das seguintes ações: (1) levantamento de artigos científicos sobre as abordagens CTS no âmbito da ECT; (2) elaboração de categorias para 
análise dos artigos, com base nos referenciais teóricos apresentados; e (3) análise das contribuições das propostas CTS relatadas nos artigos para a formação cidadã crítica e decolonial dos estudantes. $\mathrm{Na}$ sequência, são detalhados os encaminhamentos metodológicos.

\section{Sobre o levantamento dos artigos}

Pela necessidade pragmática de definir um escopo para que essa pesquisa fosse exequível, selecionamos periódicos da área de Ensino que foram classificados pela CAPES como Qualis A1 e A2, no quadriênio 2013-2016. Para isso, utilizamos a plataforma Sucupira e consultamos o trabalho de Santos et al (2018), de maneira a selecionar apenas os periódicos com foco em ECT. Reconhecemos que os periódicos classificados como Qualis A1 e A2 não contemplam a totalidade da produção acadêmica da área de ECT e, em grande parte, estão centralizadas no eixo sul-sudeste. Entretanto, considerando o nosso intuito de potencializar o conhecimento sobre as abordagens CTS no contexto brasileiro, este recorte nos pareceu adequado pelo fato das revistas analisadas serem reconhecidas como referência pela comunidade científica, alcançando maior circulação entre os pares e contribuindo de maneira mais efetiva para a produção de sentidos sobre as abordagens CTS no Brasil.

Em cada periódico, fizemos buscas por artigos que contém as siglas CTS ou CTSA no corpo do texto. Em uma planilha, organizamos as seguintes informações sobre cada artigo: título, ano de publicação, autores, resumo e palavras-chave.

\section{Sobre a elaboração de categorias para análise dos artigos}

Realizamos a leitura do resumo de cada artigo para filtrar somente aqueles que estão diretamente relacionados a investigações sobre abordagens CTS na ECT, no contexto brasileiro. Em alguns casos, o foco do trabalho era analisar as relações CTS a partir de uma temática específica (por exemplo: agrotóxicos, aquecimento global, alimentação). Neste sentido, passamos a identificar a temática explorada em cada artigo. Quando não foi possível identificar a temática a partir do resumo, realizamos a leitura integral do artigo. Por fim, organizamos os artigos encontrados em cada periódico segundo o tema abordado nos mesmos.

Devido ao grande número de artigos analisados, agrupamos-os por afinidade, em categorias temáticas. Por exemplo, trabalhos sobre Cervejas e Cachaças, foram agrupados na categoria "Bebidas Alcoólicas"; trabalhos sobre aquecimento global, qualidade do ar, biodiversidade, sustentabilidade foram categorizados como "Impactos Socioambientais"; trabalhos em que o foco era a discussão de conceitos científicos - como entropia, física de partículas, ondas eletromagnéticas e química orgânica - foram agrupados na categoria "Abordagem Conceitual".

Conforme evidenciado nas seções anteriores, adotamos uma concepção para o processo de formação cidadã crítica e decolonial dos estudantes a partir da articulação de pressupostos teóricos já colocados. Entendemos que o processo de formação cidadã crítica e decolonial está ancorado em dois momentos (interdependentes e simultâneos): a denúncia das contradições e o anúncio de formas de superação. Nesse sentido, analisamos os artigos quanto à natureza das denúncias realizadas nas propostas CTS e à natureza dos conhecimentos articulados, para anunciar formas de superação dessas contradições. 


\section{Sobre a análise das propostas CTS relatadas nos artigos}

Levando em consideração as categorias apresentadas anteriormente, desenvolvemos uma primeira análise referente à natureza das denúncias realizadas nas propostas CTS. Para isso verificamos a abrangência da temática abordada em cada artigo.

Alguns artigos apresentam investigações sobre propostas CTS que problematizam contradições de cunho universal, como: aquecimento global, astronomia, energia, combustíveis. A partir da leitura dos artigos, separamos aqueles com temática universal, daqueles que tratam de temáticas locais, por exemplo, o tratamento de água em um rio que passa no bairro da escola.

Nossos pressupostos apontam para práticas socialmente referenciadas, por isso, demos maior destaque àqueles artigos que tratavam de temáticas locais. Considerando apenas os artigos com temáticas locais, investigamos, a partir da leitura integral do trabalho, se e como eles apresentam as contradições relacionadas aos efeitos de colonialidade, incluindo o racismo, o machismo e as condições de exploração no trabalho. Nesse grupo de artigos, analisamos também quais formas de superação das contradições foram utilizadas, de maneira a identificar se outras epistemologias, além da ciência moderna e hegemônica, foram articuladas no anúncio de soluções para aquela situação de opressão.

Com essa trajetória de pesquisa, visamos contribuir para o entendimento sobre as contribuições das diversas abordagens CTS, no âmbito da ECT, para o desenvolvimento da formação cidadã crítica e decolonial dos estudantes brasileiros.

\section{Ensino de Ciências nas perspectivas CTS e a formação cidadã crítica e decolonial}

Analisamos aqui os artigos presentes em periódicos classificados como Qualis A1 e Qualis A2 da área de Ensino, com foco em ECT. O Quadro 1 apresenta o nome dos periódicos consultados, bem como o número correspondente a quantidade de artigos relacionados às abordagens CTS na ECT encontrados em cada revista científica.

Quadro 1. Periódicos pesquisados e número de artigos CTS encontrados

\begin{tabular}{|l|c|}
\hline \multicolumn{1}{|c|}{ Periódico } & Número de Artigos CTS \\
\hline Ensaio: Pesquisa em Educação em Ciências & 7 \\
\hline Acta Scientiae: Revista de Ensino de Ciências e Matemática & 4 \\
\hline Alexandria & 24 \\
\hline Amazônia - Revista de Educação em Ciências e Matemáticas (Online) & 11 \\
\hline Dynamis & 4 \\
\hline Investigações em Ensino de Ciências & 8 \\
\hline Praxis & 3 \\
\hline Revista Brasileira de Ensino de Ciência e Tecnologia & 18 \\
\hline
\end{tabular}




\begin{tabular}{|l|c|} 
Revista Brasileira de Pesquisa em Educação em Ciências & 18 \\
\hline Revista de Educação, Ciências e Matemática & 3 \\
\hline Revista de Ensino de Ciências e Matemática (RENCIMA) & 31 \\
\hline Areté - Revista Amazônica de Ensino de Ciências & $\mathbf{1 3 9}$ \\
\hline \multicolumn{1}{c}{ Total } & \\
\hline
\end{tabular}

Fonte: Elaborado pelos autores.

Dos 139 artigos encontrados, 66 explicitam relatos de investigação sobre abordagens CTS a partir de temáticas específicas. No Quadro 2, apresentamos as categorias temáticas encontradas, bem como o número de artigos que apresentam discussões sobre cada um dos temas. Em alguns artigos, há discussões sobre mais de uma temática e, por isso, a soma dos números no Quadro 2 não corresponde ao total de artigos analisados nesta etapa (66).

Quadro 2. Categorias temáticas dos trabalhos analisados

\begin{tabular}{|c|c|}
\hline Categorias Temáticas & Quantidade de artigos \\
\hline Abordagem Conceitual & 5 \\
\hline Agrotóxicos & 5 \\
\hline Alimentação & 3 \\
\hline Amazônia & 2 \\
\hline Astronomia & 1 \\
\hline Bebidas Alcoólicas & 3 \\
\hline Combustíveis Fósseis & 5 \\
\hline Desigualdade Social & 1 \\
\hline Empreendedorismo & 1 \\
\hline Energia & 4 \\
\hline Gênero E Sexualidade & 1 \\
\hline Genética & 1 \\
\hline Impactos Socioambientais & 16 \\
\hline Mobilidade Urbana & 1 \\
\hline Polímeros & 3 \\
\hline Radioatividade & 1 \\
\hline Resíduos/Lixo & 6 \\
\hline Sabão & 2 \\
\hline
\end{tabular}




\begin{tabular}{|c|c|} 
Saúde & 3 \\
\hline Tecnologia & 3 \\
\hline
\end{tabular}

Fonte: Elaborado pelos autores.

A partir da análise desses artigos, à luz dos pressupostos teóricos apresentados, discutimos sobre a natureza das denúncias realizadas nas propostas CTS, bem como a natureza dos conhecimentos articulados nos anúncios de formas de superação dessas contradições.

A categoria "Abordagem Conceitual" está presente em 5 artigos, o que pode ser reflexo de uma das várias concepções sobre o ensino de Ciências a partir das relações CTS. Em alguns casos, as abordagens CTS são reduzidas a uma metodologia de ensino e todas as imbricações sociais e tecnológicas relacionadas ao tema estudado surgem como exemplificação, ou aplicação para facilitar a aprendizagem de determinado conceito científico.

Nos casos em que os estudantes vivenciam abordagens CTS com foco em algum conceito científico, há destaque para o aumento do interesse dos mesmos pelo processo de ensino e aprendizagem, conforme apresentado em alguns dos artigos da categoria "Abordagem Conceitual".

(...) consideramos que a implementação da sequência didática devidamente planejada e estruturada com diferentes recursos de ensino e sob uma perspectiva das relações CTS, gerou um ambiente de aprendizagem completamente diferente do tradicionalmente adotado por muitos professores, permitindo assim que os alunos num estágio de motivação se tornassem corresponsáveis pelo processo de ensino e aprendizagem (GOMES; BATISTA; FUSINATO, 2017, p.123).

(...) deve-se oferecer aos discentes condições para a discussão de temas de seu cotidiano que promovam interesse pela busca e construção do conhecimento, como observamos na prática desenvolvida (VASCONCELOS; ANDRADE, 2017, p.11)

Santos e Mortimer (2002) classificam essa abordagem como "Conteúdo de CTS como elemento de motivação". Os autores descrevem essa categoria como "Ensino tradicional de ciências acrescido de menção ao conteúdo de CTS com a função de tornar as aulas mais interessantes" (SANTOS; MORTIMER, 2002, p.124). Ainda que consideremos positivo o aumento de engajamento dos estudantes, defendemos que a promoção da ECT a partir das relações CTS pode ir além. Parece-nos que, em alguns casos, a formação cidadã é preterida em função da aprendizagem de conceitos científicos em perspectiva supostamente neutra, ou seja, sem relacioná-los autenticamente ao contexto social ou tecnológico dos estudantes, o que contribui para a adaptação e consequente manutenção das estruturas opressoras.

Ademais, a partir do Quadro 2, podemos observar que algumas temáticas fogem da realidade concreta dos estudantes. Com o intuito de observar essa hipótese com mais cuidado, nos propomos investigar a abrangência da temática CTS estudada em cada um dos 66 artigos. Classificamos a abrangência dos temas como "universal" ou "local".

Os temas universais são aqueles que não estão relacionados à comunidade dos estudantes de maneira arraigada. Por exemplo, os artigos que constituem a categoria "Impactos Socioambientais", em sua maioria, apresentam temáticas universais, como o aquecimento global, a chuva ácida e a preservação de recursos naturais. Ainda que esses 
fenômenos abranjam todo o globo terrestre, eles não são parte das contradições específicas e concretas da comunidade dos estudantes.

Já as temáticas locais estão diretamente imbricadas com o cotidiano da comunidade escolar, conforme é possível perceber em um dos artigos que consideramos ter abrangência local.

(...) durante as discussões sobre mudanças no cenário do Arroio Cadena, foi possível perceber que a ação individual não atenderia o problema da comunidade e chegou-se à conclusão que, possivelmente, com intervenções das Políticas Públicas, poderia acontecer alguma mudança ou iniciativa (CENTA; MUENCHEN, 2016, p.283).

Dos 66 artigos analisados, $52(79 \%)$ apresentam temática universal, enquanto 14 (21\%) foram categorizados como temas locais. Essa discrepância numérica não é casual. Conforme comentado anteriormente, a educação CTS foi inserida no contexto brasileiro, via Parâmetros Curriculares Nacionais, sob forte influência da perspectiva CTS europeia, particularmente da vertente espanhola. Podemos dizer que esses documentos são baseados em reflexões e ações próprias de contextos eurocêntricos e caracterizam a colonialidade do saber. A incorporação de temáticas e práticas eurocentradas produzem um efeito de colonialidade, que, por sua vez, produz a invisibilização de problemas e temas de interesse local e regional, que seriam muito mais significativos e relevantes para uma formação cidadã crítica.

Os dados apresentados anteriormente, ainda que não correspondam à totalidade do campo de pesquisa, representam parte considerável da produção acadêmica brasileira sobre abordagens CTS na ECT e asseveram a validade das considerações realizadas a respeito dos efeitos de colonialidade (QUIJANO, 1992) que têm operado também em nossas práticas escolares, quando as problemáticas locais são silenciadas em favor de pautas externas.

Cassiani, Linsingen e Pereira (2016) analisam esses efeitos de colonialidade em Timor-Leste, a partir do conceito de transnacionalização de currículo. Resumidamente, este conceito se refere à transferência de saberes de um país para outro, sem levar em conta as realidades locais. Freire (1974) já havia observado isso, quando escreveu que os guineenses precisavam estudar seus rios e não os rios de Portugal, e seu povo e não a corte portuguesa.

Nesse sentido e como alternativa, defendemos a articulação dos pressupostos de Paulo Freire no contexto escolar, de modo a identificar temáticas coerentes ao contexto dos estudantes, assim como fizeram as autoras Centa e Muenchen (2016). O uso de temas universais pode jogar uma cortina de fumaça sobre as problemáticas concretas dos estudantes, contribuindo muito mais para adaptação à realidade opressora do que para sua transformação, conforme adverte Freire (1987). Ademais, a articulação desses temas universais pode gerar nesses sujeitos um sentimento de que o ambiente escolar, bem como os conhecimentos e as práticas que ocorrem ali, está apartado da comunidade local.

Consideramos fundamental que as temáticas locais tenham prioridade sobre as globais, e que as globais possuam algum nível de relação com as realidades locais. Por outro lado, há que se considerar que a ECT promovida a partir de temas locais, do contexto dos estudantes, não necessariamente está comprometida com a formação cidadã crítica e decolonial. Por vezes, alguns temas, com potência para ensejar a transformação da 
realidade, têm alguns sentidos esvaziados e as contradições típicas do colonialismo e do Sul Global naquele contexto são silenciadas.

Nesse sentido, nos dedicamos a identificar, dentre os artigos com temáticas locais, como eles tratam das contradições tão caras à formação crítica dos estudantes, como o racismo, o patriarcado ou as condições de exploração do trabalho no sistema capitalista. Justificamos essa escolha por perceber que muitos de nós, pesquisadores e professores comprometidos com a formação cidadã, muitas vezes, nos perdemos neste objetivo e contribuímos para silenciar questões muito importantes à transformação da nossa sociedade.

A partir da leitura integral dos artigos, identificamos que, nos 14 trabalhos categorizados como "temáticas locais", as contradições oriundas dos efeitos de colonialidade, típicas do Sul Global, são pouco abordadas. A seguir, apresentamos alguns exemplos com o intuito de evidenciar como ocorre o silenciamento de algumas contradições opressoras típicas do nosso contexto. Como pesquisadores da área de ECT, nosso exercício é de autocrítica para que possamos, em conjunto, aprender sobre e vivenciar práticas escolares socialmente referenciadas e libertadoras.

Citamos aqui o trabalho de Milli, Almeida e Gehlen (2018) como um exemplo de comprometimento com a realidade concreta dos estudantes. Neste trabalho, inspiradas pela investigação temática proposta por Freire, as autoras relatam e analisam o processo de escolha de uma temática a ser discutida em escolas do município de Santa Luzia, na Bahia. Neste processo, foi definida a temática: “'Lazer', violência e trânsito: roubando vidas em Santa Luzia?".

A unidade II da proposta didática apresentada no artigo analisado é direcionada para a questão da Violência no município Santa Luzia (BA). No artigo, são destacados os seguintes conteúdos e conceitos científicos integradores dessa unidade: (i) Tipos de violências (simbólica, física, abusos, etc.); (ii): corpo humano; (iii) educação sexual (gravidez, aborto, etc.). Entretanto, a leitura integral do artigo não nos permitiu perceber a articulação desses tipos de violência ao machismo, ao patriarcado e ao racismo.

Provavelmente, os sujeitos que mais sofrem com esse tipo de violência no município de Santa Luzia (BA) são as mulheres negras e esse possível fato nos parece ter sido silenciado (não que essa fosse a intenção dos sujeitos envolvidos no processo). Nesse sentido, o foco da denúncia poderia estar nos efeitos de colonialidade associados ao racismo e ao machismo. Nesse caso, para além do entendimento científico sobre o corpo humano e a educação sexual, outros conhecimentos, como os estudos feministas e do movimento negro, poderiam ter sido articulados para favorecer uma formação cidadã crítica e decolonial às (aos) estudantes.

Ao analisar o trabalho de Milli, Almeida e Gehlen (2018), fica evidente sua criticidade e seu compromisso com a realidade concreta dos estudantes. Contudo, defendemos que a formação cidadã, no nosso contexto, deve ser também decolonial, evidenciando que nossas contradições estão intimamente relacionadas à pressupostos que inferiorizam e violentam os sujeitos a partir da raça (negra, indígena e qualquer outra que não seja a branca; com gênero feminino (ou qualquer outro que não seja masculino); e/ou pela condição de exploração do trabalho no sistema capitalista.

Em um outro artigo que trata de questões locais, as autoras Pereira, Silveira e Junior (2013) analisaram uma proposta didática CTS em uma escola do campo no 
município de Imbituva (Paraná), onde aproximadamente 90\% são filhos de fumicultores. Segundo as autoras, os temas trabalhados foram: produção Brasileira de tabacos; evolução da cultura de tabacos; produção Regional de tabacos; e impactos na saúde dos fumicultores. A finalização do trabalho se deu com uma apresentação dos estudantes à comunidade local.

No que se refere aos impactos na saúde, foram apresentadas as falas de alguns estudantes relatando sintomas sentidos pelos pais (trabalhadores) e as autoras afirmam que a "cultura de tabacos é uma cultura dependente da política social onde (...) a qualidade de vida pode estar em decadência" (PEREIRA; SILVEIRA; JÚNIOR, 2013, p. 94). As autoras atribuem a decadência da qualidade de vida, principalmente, com o uso indiscriminado de agrotóxicos.

Entretanto, não fica evidente no artigo se houve discussões sobre os fatores que acarretam tal uso, além da aparente ausência de debates sobre formas de superação dessas contradições oriundas do mundo do trabalho. Historicamente, os fumicultores têm recebido apoio e financiamento de indústrias do ramo de cigarros, que, em contrapartida, exigem elevada produtividade dos agricultores. Nesse sentido, é gerada uma relação de exploração e dependência dos fumicultores, que tradicionalmente envolvem toda a família no plantio e na colheita do fumo (VARGAS, 2002).

Ao que nos parece, essas questões de exploração na relação de trabalho, típicas do sistema capitalista, foram silenciadas na proposta CTS apresentada por Pereira, Silveira e Júnior (2013). Nesse caso, ainda que a denúncia apresentada tenha caráter local - uma vez que está concretamente relacionada à realidade dos estudantes - ela poderia ser aprofundada, de maneira a atingir o cerne das contradições vivenciadas pelos estudantes. Além disso, os estudantes poderiam articular conhecimentos indígenas ou dos movimentos sociais do campo para, de maneira propositiva, anunciar formas de superação das estruturas opressoras a que eles e suas famílias estão sujeitas. Nesse sentido, denunciando as mazelas do capitalismo e anunciando soluções com base em conhecimentos alternativos, acreditamos que poderia ser favorecida uma formação cidadã crítica e decolonial.

\section{CONSIDERAÇÕES FINAIS}

As abordagens CTS, amplamente divulgadas na literatura, têm elevado potencial para contribuir com a formação dos estudantes no que se refere ao exercício da cidadania. Entretanto, algumas características dessas abordagens precisam ser ressignificadas para que a ECT contribua para a formação cidadã crítica e decolonial dos estudantes.

Muitas propostas CTS são desenvolvidas a partir da incorporação de temáticas universais, que entendemos ser um efeito de colonialidade atuando sobre as escolhas temáticas dos professores e pesquisadores em ECT. Além disso, não percebemos, no corpo dos artigos analisados neste trabalho, que as propostas CTS têm se voltado a realizar denúncias sobre as contradições que mantêm sistematicamente as estruturas de opressão na nossa sociedade (ex. racismo, machismo e capitalismo), ainda que muitas das problemáticas desenvolvidas nas propostas didáticas estejam intimamente relacionadas a elas.

Ademais, destacamos que não foi possível perceber outras formas de conhecimento, para além da Ciência moderna hegemônica, serem articuladas no anúncio de soluções para as contradições. Nesse sentido, entendemos que essas propostas educacionais não têm tido caráter inovador e transgressor, o que provavelmente contribui 
para nossa adaptação às formas opressoras de viver. Concordando com Boaventura de Sousa Santos e Maria Paula Meneses (2014), precisamos avançar no sentido de identificar e valorizar outros marcos epistemológicos para que a prática seja também inovadora e libertadora, culminando em uma sociedade com mais justiça social e menos opressão.

Com base no que aqui foi discutido, defendemos que as abordagens CTS sejam críticas e decoloniais. Para isso, é necessário ressignificar alguns elementos dessas abordagens no âmbito da ECT, de maneira a dar oportunidade aos estudantes a realização de denúncias das contradições que os cercam, bem como de anúncios de formas de superação das mesmas. Nesse sentido, consideramos que é fundamental que os estudos decoloniais sejam articulados a essas propostas pedagógicas, como forma de superar os efeitos de colonialidade aqui tratados.

Para superar essas contradições, defendemos que o tratamento horizontal de saberes constitua a base da ECT. Nesse sentido, cabe aos educadores e pesquisadores da área identificar e dar visibilidade a esses conhecimentos que historicamente foram silenciados em prol de fatores como a validade e a universalidade da Ciência moderna hegemônica. Acreditamos que, a partir da articulação desses conhecimentos, podem surgir formas inovadoras de superação das estruturas de opressão que inibem os processos de transformação social.

\section{REFERÊNCIAS}

ARGO, Grupo. Ciencia, Tecnología y Sociedad. Materiales para la educación CTS. Grupo Editorial Norte. España, 2001.

AULER, Décio; BAZZO, Walter Antonio. Reflexões para a implementação do movimento CTS no contexto educacional brasileiro. Ciência \& Educação (Bauru), v. 7, n. 1, p. 1-13, 2001.

AULER, Décio; DELIZOICOV, Demétrio. Ciência-Tecnologia-Sociedade: relações estabelecidas por professores de ciências. Revista electrónica de enseñanza de las ciencias, v. 5, n. 2, p. 337-355, 2006.

BRASIL, L. D. B. Lei 9394/96-Lei de Diretrizes e Bases da Educação Nacional. Disponível http://www. planalto. gov. br/ccivil_03/leis/19394. htm. Acesso em 09 de março de 2019, 1996.

CARNAÚBA, Maria Érbia Cássia. Sobre a distinção entre teoria tradicional e teoria crítica em Max Horkheimer. Kínesis-Revista de Estudos dos Pós-Graduandos em Filosofia, v. 2, n. 03, 2010.

CASSIANI, S; LINSINGEN, Irlan von; PEREIRA, P. B. (Pre)textos para pensar a cooperação educacional em Timor-Leste: algumas referências para o internacionalismo solidário. PERSPECTIVA (UFSC) (ONLINE), v. 34, p. 390-414, 2016.

CASTRO-GÓMEZ, Santiago. La hybris del punto cero: ciencia, raza e ilustración en la Nueva Granada (1750-1816). Edtitorial Pontificia Universidad Javeriana, 2010.

CENTA, Fernanda Gall; MUENCHEN, Cristiane. O Despertar para uma Cultura de Participação no Trabalho com um Tema Gerador. Alexandria: Revista de Educação em Ciência e Tecnologia, v. 9, n. 1, p. 263-291, 2016. 
CHRISPINO, Alvaro et al. A área CTS no Brasil vista como rede social: onde aprendemos?. Ciência \& Educação, v. 19, n. 2, p. 455-479, 2013.

DA SILVA ROSA, Paulo Ricardo. Fatores que influenciam o ensino de ciências e suas implicações sobre os curricula dos cursos de formação de professores. Caderno Brasileiro de Ensino de Física, v. 16, n. 3, p. 287-313, 1999.

DAGNINO, Evelina. Sociedade civil, participação e cidadania: de que estamos falando. Políticas de ciudadanía y sociedad civil en tiempos de globalización. Caracas: FACES, Universidad Central de Venezuela, p. 95-110, 2004.

FREIRE, Paulo. Cartas a Guiné Bissau. Rio de Janeiro: Paz e Terra, 1974.

FREIRE, Paulo. Pedagogia do Oprimido. 17. ed. Rio de Janeiro: Paz e Terra, v. 4, n. 6, 1987.

GALANTE, Luciana. Investigação etnobotânica entre os Guarani Mbya de Tekoa Pyau. Dissertação (Mestrado em Ciências Sociais) - Pontifícia Universidade Católica de São Paulo, São Paulo, 2011.

GOMES, Ederson Carlos; BATISTA, Michel Corci; FUSINATO, Polonia Altoé. O estudo das ondas eletromagnéticas a partir do enfoque CTS: uma possibilidade para o ensino de física no ensino médio. Revista de Ensino de Ciências e Matemática, v. 8, n. 1, p. 109-125, 2017.

HECKLER, Jacimara Machado. Sementes E Saberes... Trocas e aprendizados com a cultura Guarani e a agroecologia. Tese de Doutorado. Universidade Federal do Rio Grande do Sul. Faculdade de Educação, Porto Alegre, 2006.

KRASILCHIK, Myriam. Reformas e realidade: o caso do ensino das ciências. São Paulo em perspectiva, v. 14, n. 1, p. 85-93, 2000.

LINSINGEN, Irlan Von. Perspectiva educacional CTS: aspectos de um campo em consolidação na América Latina. Ciência \& Ensino (ISSN 1980-8631), v. 1, 2008.

LINSINGEN, Irlan Von; CASSIANI, Suzani. Educação CTS em perspectiva discursiva: contribuições dos estudos sociais da Ciência e da Tecnologia. Anais do VIII Encontro Nacional de Pesquisa em Educação em Ciências, 2010.

MILLI, Júlio César Lemos; DOS SANTOS ALMEIDA, Eliane; GEHLEN, Simoni Tormöhlen. A rede temática e o ciclo temático na busca pela cultura de participação na educação CTS. Alexandria: Revista de Educação em Ciência e Tecnologia, v. 11, n. 1, p. 71-100, 2018.

MORTATTI, Maria do Rosario Longo. Alfabetização, política e democracia: impactos do passado em pactos do presente (em defesa de paulo freire como "patrono da educação brasileira"). Perspectivas em Diálogo: revista de educação e sociedade, v. 5, n. 10, p. 5$32,2019$.

MOURA, Lino Geraldo Vargas. Indicadores para a avaliação da sustentabilidade em sistemas de produção da agricultura familiar: o caso dos fumicultores de Agudo-RS. 2002 .

NASCIMENTO, Tatiana Galieta; VON LINSINGEN, Irlan. Articulações en tre o enfoque CTS ea pedagogia de Paulo Freire como base para o ensino de ciências. Convergencia Revista de Ciencias Sociales, n. 42, 2006. 
PEREIRA, Luciana Boemer Cesar; SILVEIRA, Rosemari Monteiro Castilho Foggiatto; DOS PORTO-GONÇALVES, C. W. in LANDER, E. (org). A colonialidade do saber: eurocentrismo e ciĺncias sociais Perspectivas latino-americanas. Colecciun Sur Sur, CLACSO, Ciudad Autônoma de Buenos Aires, Argentina. setembro 2005.

QUIJANO, Aníbal. ; Qué tal raza!. Revista venezolana de economía y ciencias sociales, v. 6, n. 1, p. 37-45, 2000.

QUIJANO, Aníbal. Colonialidad y modernidad/racionalidad. Perú indígena, v. 13, n. 29, p. 11-20, 1992.

ROSO, Caetano Castro; AULER, Décio. A participação na construção do currículo: práticas educativas vinculadas ao movimento CTS. Ciência \& Educação, v. 22, n. 2, p. 371-389, 2016.

SANTOS JUNIOR, Guataçara. Ensino de estatística com enfoque CTS: uma articulação entre matemática e temas sociais. Revista Práxis, v. 5, n. 10, 2013.

SANTOS, Saulo Cézar Seiffert et al. Análise dos periódicos qualis/capes: visão geral da área de ensino em ciências e matemática analysis of qualis/capes periodicals: overview of the area in of science and mathematics education. Revista Brasileira de Educação em Ciências e Educação Matemática, v. 2, n. 1, p.106-126, 2018.

SANTOS, W. L. P. dos; MORTIMER, E. F. Uma Análise de Pressupostos Teóricos da Abordagem C-T-S (Ciência-Tecnologia-Sociedade) no Contexto da Educação Brasileira. Ensaio - pesquisa em educação em ciências, v.2, n.2, p.133-162, 2002.

SANTOS, Wildson Luiz Pereira dos. Educação científica humanística em uma perspectiva freireana: resgatando a função do ensino de CTS. Alexandria: revista de educação em ciência e tecnologia, v. 1, n. 1, p. 109-131, 2008.

SOUSA SANTOS, Boaventura de. A gramática do tempo: para uma nova cultura política. Edições Afrontamento, 2006.

SOUSA SANTOS, Boaventura de; MENESES, Maria Paula. Epistemologias do sul. São Paulo: Cortez, 2014.

STRIEDER, Roseline Beatriz. Abordagem CTS e ensino médio: espaços de articulação. 2008. Tese de Doutorado. Universidade de São Paulo.

STRIEDER, Roseline Beatriz; KAWAMURA, Maria Regina Dubeux. Educação CTS: parâmetros e propósitos brasileiros. Alexandria: Revista de Educação em Ciência e Tecnologia, v. 10, n. 1, p. 27-56, 2017.

TONET, Ivo. Cidadania ou emancipação humana. Revista espaço acadêmico, n. 44, p. 1$10,2005$.

VASCONCELOS, Carlos Alberto de; ANDRADE, Bruno dos Santos. Abordagem da separação de misturas no ensino fundamental sob o enfoque CTSA visando a contextualização no ensino de ciências. Revista de Ensino de Ciências e Matemática, 2017.

WAISELFISZ, Julio Jacobo. Mapa da violência 2013: homicídios e juventude no Brasil. 2013.

WALSH, Catherine. Interculturalidade crítica e pedagogia decolonial: in-surgir, re-existir e re-viver. Educação intercultural na América Latina: entre concepções, tensões $e$ propostas. Rio de Janeiro, v. 7, p. 12-42, 2009. 
YAGER, Robert E. The history and future of science education reform. The Clearing House: A Journal of Educational Strategies, Issues and Ideas, v. 74, n. 1, p. 51-51, 2000.

Recebido em: 09/11/2018

Aprovado em: 13/01/2019 